\title{
FRAGMENTOS DEL GRAN COMENTARIO DE AVERROES A LA FÍSICA
}

\section{FRAGMENTS FROM AVERROES' LONG COMMENTARY ON THE PHYSICS}

\author{
Joser PUig Montada \\ Universidad Complutense de Madrid
}

El manuscrito árabe número 5.000 de la $\mathrm{Bi}$ blioteca Nacional de Madrid contiene los epítomes o comentarios menores de Averroes a varias obras de Aristóteles. Unas anotaciones marginales al principio del epítome de la $F^{i}$ sica resultan ser fragmentos del comentario mayor de Averroes a la obra de Aristóteles. Estos fragmentos son el objeto principal del artículo puesto que son los únicos testimonios del original árabe. El artículo considera también anotaciones de los propietarios del códice en árabe y en caracteres árabes, en árabe, en caracteres hebreos y alguna palabra hebrea, y en latín, a veces correcto, otras más bien romance; el latín puede aparecer en escritura gótica o en caracteres hebreos.

Palabras clave: Averroes; Aristóteles; Comentario Mayor-Averroes; Física-Aristóteles.
The Arabic manuscript 5000 of the National Library in Madrid contains Averroes' epitomes or short commentaries on various works of Aristotle. Annotations written on the margins of the short commentary on the Physics appear to be fragments of the long commentary on this work of Aristotle. The article focuses on the fragments because they are the only evidence of the Arabic original. Further, the article considers notes written by the successive owners of the manuscript: some are written in Arabic and in Arabic letters, others in Arabic and Hebrew letters (some words are also in Hebrew) and others are written in Vulgar Latin, either in Hebrew or Latin letters.

Key words: Averroes; Aristotle; Long Commentary-Averroes; Physics-Aristotle.

El manuscrito árabe número 5.000 de la Biblioteca Nacional de Madrid contiene los epítomes o comentarios menores de Averroes al grupo de escritos naturales de Aristóteles, compuesto por la Física, Acerca de la generación y la corrupción, Acerca del cielo, y Meteorológicos así como a su escrito Acerca del alma y al de la Metafisica. En el catálogo de Francisco Guillén Robles ${ }^{1}$, el códice recibe el número XXXVII y se identifica como Libro (titulado) las Sumas. Lo describe así:

118 fols. magrebí. anotaciones marginales árabes, hebreas y latinas, éstas a veces en carmín y letra del s. XV: al principio un folio con notas árabes, hebreas y lati-

1 Catálogo de los manuscritos árabes existentes en la Biblioteca Nacional de Madrid, Madrid, 1889. 
nas: al siguiente el título de la obra en latín y árabe: después una nota de Yriarte sobre el manuscrito: al fin un folio con notas hebreas.

Hartwig Derenbourg 2 consideraba que este manuscrito (que estaba en el armario Gg. 36) era poco posterior a la muerte de Averroes (1198) y que muy probablemente era del s. XIII. Es un original de gran valor, que nunca abandonaría el suelo ibérico y que fue anotado por árabes, judíos y cristianos, como vamos a ver.

El manuscrito contiene anotaciones de cuatro clases: en árabe y con caracteres árabes, en árabe, con caracteres hebreos y alguna palabra hebrea, y en latín, a veces correcto, otras más bien romance; el latín puede aparecer en escritura gótica o en caracteres hebreos. Los caracteres hebreos deben considerarse sefardíes, del siglo XV, y la escritura gótica, también del siglo XV. Todas estas anotaciones nos revelan las huellas de sus propietarios, primero de dos discípulos árabes, luego de varios judíos y finalmente de algún cristiano.

En este artículo me ocuparé fundamentalmente de las anotaciones en árabe en los márgenes de los primeros folios. En otros márgenes las anotaciones son palabras, excepto una de cinco líneas en el margen superior de fol. 56v., todas de letra distinta a las anotaciones que son objeto principal de estudio.

En cuanto a las anotaciones en árabe con caracteres hebreos, dos tienen alguna extensión. La primera se encuentra en fol. 1v., la transcribo aquí y después de ella la translitero en caracteres árabes, poniendo entre corchetes las lecturas conjeturales:

יע[ני] תרכיב ...ל ומעני אלתרכיב [ב'] אלמקדמה אלמוגבה ואלתפצל אלסאלבה \אן יתן

אלתרכיב אלגנס ואלפצל \אלתי באגתמאעה [...] יתבן אלחד \ואלתפצל הו תחליל כל שי

אלי אגזיאה \אלדאתיה ואכדה עלי חדה.3

يعني تركيب ... ومعنى التركيب في المقدمة الموجبة والتقصل السالبة أن [يتبين] التركيب الجنس

والفصل التي باجتماعه [... يتبين] الحدَ، والتفصل هو تحليل كلَ شيء إلى أجزائه الذاتية وأخذه

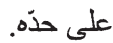

2 Notes critiques sur les manuscrits arabes de la Bibliothèque Nationale de Madrid, París, 1904, 11-12.

${ }_{3}$ Agradezco la ayuda del Prof. H.A. Davidson, Los Ángeles, para descifrar el fragmento.

Al-Qanțara (AQ) XXX 1, enero-junio 2009, pp. 69-81 ISSN 0211-3589 
Es una anotación de tipo lógico, acerca de los conceptos de «síntesis» (tarkïb) y «análisis» (taḥlïl), que no parece proceder de ninguna obra de Averroes. Por otra parte, la anotación, en árabe con caracteres hebreos en el último folio (121v.), que es de mano diferente, es una copia de un pasaje donde un autor desconocido inquiere si el alma racional y los ángeles tienen definición o no. Por su temática suponemos que este autor vivía ya en la España cristiana. El párrafo empieza así:

ינטר פי אלנפס אלנאטקה ואלמלאיכה הל להא חד אם לא

$$
\text { ينظر في النفس الناطقة والملانكة هل لها حذَ ام لا. }
$$

Observemos que este mismo folio $121 \mathrm{v}$. contiene unas anotaciones contables, en hebreo, sin interés para el artículo. En cuanto a las palabras latinas, éstas aparecen a menudo como títulos en los márgenes del códice y también al comienzo. Folio 2 r. es la portada original:

$$
\text { كتاب الجوامع، تأليف الفقيه القاضي ابي الوليد بن رشد، رحمه الله }
$$

Encima está su traducción en latín: liber summarum aberrosis super libros aristotelis. Además, el fol. 1r., recortado, permite leer el final de esta anotación: omnes libros naturales aristotelis et suam metafisicam. En este mismo fol. 1r. llaman la atención unas frases bilingües, latín en escritura gótica y árabe en caracteres hebreos,

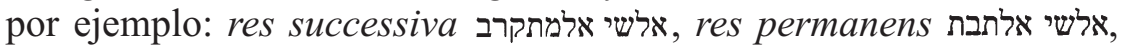
microcosmus אלעלם אלאצגר, macrocosmus מלעלם אלאעזם, motus rectus חרכה מסתקימה motus erectans חרכלה (conjetura:) מסתלירה .

De mano distinta son otras frases en caracteres hebreos, pero de lengua latina, por ejemplo:

פוטינתיאה איט פושיביליטאש אינדגינט שובגקט , fol. 1r., y el texto latino potentia et posibilitas indigent subjecto aparece en el margen derecho del fol. 4 r.

פol. 1r., y el latín prima materia in generabilibus et in corruptibilibus aparece en el margen izquierdo del fol. $4 \mathrm{r}$.

De la misma mano son una veintena de frases bilingües del fol. 1r., donde todos los caracteres son hebreos, por ejemplo nichilo abso-

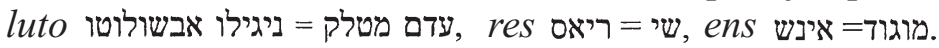


Son frases que podemos considerar como indicios apuntando a un traductor, o simplemente como curiosidades. Curiosidad es una nota más romance que latina en caracteres hebreos del fol. 1v. La mano es distinta de las anteriores, y el autor conocía el latín muy poco (por ejemplo, leemos auferatu por auferatur), y predominan los elementos romances; la lengua es del siglo XIV o XV. Se trata de una advertencia a quien robase el códice, advertencia frecuente, y extiende ésta a quien conociera el hurto, o a quien hallare el libro y lo escondiere.

$$
\begin{aligned}
& \text { כב מה אופיראתו ינטליקטוש אישט קידטאט [בס] אכיבנדב } \\
& \text { שיקונץ אופיראתו אישט קונפוניב ולדבדב } \\
& \text { טירסט אופיראתו איקש נוטיש שי לו גיתאב אט קונקלודב. }
\end{aligned}
$$

Mi trascripción, conjetural y adaptando la ortografía latina, es la siguiente:

cave mihi auferatu, intellectus est qui datate [vos] a qui vendebe si conoz auferatu est cunpunibe o-l dividebe te rest auferatu ex notis si lo gitabe et concludebe

$$
* * *
$$

Para nuestro estudio, mayor interés tienen unas anotaciones marginales al principio del epítome de la Física en los folios que contienen los libros I y II del compendio averroico de la Física. Su importancia se debe a que son fragmentos del comentario mayor de Averroes a la obra de Aristóteles, y es mayor todavía porque este comentario no se ha conservado más que en las traducciones medievales, latina o hebrea ${ }^{4}$. Estos fragmentos son los únicos testimonios del original árabe.

En este trabajo he transcrito estos fragmentos cuya ortografía es la propia del árabe medio. Como el sonido hamza ha desaparecido, solamente el manuscrito lo escribe wāw o y $\bar{a}$; ; el älif maqșüra lo escribe con puntos diacríticos. He añadido el signo tašdi d cuando pertenece a la raíz y también el alif hamza, para facilitar la lectura. Entre «corche-

${ }^{4}$ Enciclopedia de la cultura andalusí, Biblioteca de al-Andalus, 4, Almería, 2005, 572.

Al-Qanțara (AQ) XXX 1, enero-junio 2009, pp. 69-81 ISSN 0211-3589 
tes» pongo mi lectura conjetural, entre «ángulos», palabras repetidas y entre «paréntesis», aquellas frases que no proceden del comentario de Averroes, sino que son la presentación del autor de la nota; a continuación doy su traducción española. Finalmente transcribo el texto latino tomado de Quartum Volumen. Aristotelis de Physico Auditv libri octo, cum Averrois [...] commentariis, Venetiis, apvd Iunctas, 1562. De acuerdo con los estudios de Horst Schmieja, Colonia, que prepara la edición crítica del Comentario Mayor dentro del proyecto de edición de las obras de Averroes, los editores venecianos utilizaron también un manuscrito latino de una familia de manuscritos ingleses cuyo representante más destacado es Worcester, Chapt. Library, F. 96 (AL 388). El Dr. Schmieja me ha facilitado tanto las variantes de Worcester (sigla Wf) respecto de Venecia, como las de otros dos manuscritos, Toledo, Biblioteca Capitular 97 y París, BN, lat. 15.453 (AL 654), de familias distintas. Dado que las variantes se revelan como importantes solamente en el caso del fragmento 5, no las doy más que en este caso.

Fragmentos del gran comentario a la Física

Madrid BN, f. 4a

(يقول القاضي صاحب هذا الكتاب في شرحه لكتاب الحكيم في [م..] موضع) المادّة

والصورة ليس توجد مفارقة بالوجود إنما توجد مفارقة بالقول وذللك أن الصورة الوجود لها [من

حيث] هي بالفعل وأما الهيولي [من] حيث هي بالقوة

In Phys. 190 b 17

Dice el juez, autor de este libro en su comentario (mayor) al libro del sabio (Aristóteles) en [...] lugar «La materia y la forma, no existe separada en la existencia, solamente existe separada de palabra, porque la forma tiene existencia por cuanto está en acto, y la materia prima, en cuanto está en potencia».

Quartum Volumen. Aristotelis de Physico Auditv libri octo, cum Averrois [...] commentariis. Venetiis, 1562. 
F 39 D, Lib. I (t.c. 65) potest enim dissoluere rationem materiae, et formae, et distinguere eas secundum definitionem, et licet non in esse: non enim separantur a seinuicem in esse, licet separentur ratione.

(يقول القاضي في هذه المقالة الثانية) فابنا نقول نحن إن الهيولي من جهة ما لحقها العدم

صار لها من شأنها وبقسر طبيعته أن تشتوق إلى التشبه بالمبدأ حسب ما بطاقتها وذلك هو تشوقها

إلى قبول الصورة، ونعني هاهنا بالتشوق الاستعرائ الطبيعي الذي في الهيولي لقبول الصورة

$$
\text { (وإنما سماه تشوقا على جهة الاستعارة ) }
$$

In Phys. 192 a 17

Dice el juez, en este segundo libro: «Nosotros afirmamos que la materia prima en cuanto le afecta la privación, a causa de su manera de ser y por la fuerza de su naturaleza desea asimilarse al principio en la medida de su capacidad, porque su deseo es recibir la forma, y aquí expresamos por «deseo» la predisposición natural que hay en la materia prima para recibir la forma». Solamente lo denominan «deseo» metafóricamente.

F 46 D Lib. I (t.c. 81) dicimus nos quod materia, secundum quod accidit ei priuatio, est innata appetere se assimilari primo principio secundum quod potest, et hoc es appetere receptionem formae. Et intelligit hic per appetitum illud, quod materia habet de motu ad recipiendum formam.

يقول القاضي في الشرح الكبير الصورة هي الذكر و المادة الأنثى من العلم

In Phys. 192 a 17

Dice el juez en el comentario mayor: «La forma es el macho, y la materia, la hembra, en la ciencia».

Al-Qanțara (AQ) XXX 1, enero-junio 2009, pp. 69-81 ISSN 0211-3589 
f. 46 F, Lib. I (t.c. 83): materia appetit formam sicut foemina marem.

( من الشرح)، والذي يظهر هنالك أن المادة إنما هي جوهر بالقوة وأن الصورة حوأن

الصورة> هي التي من قَلها صار الموجود جوهر ا بالفعل فالمركب أحقّ باسم الجوهر من الهيولي

لأنه بالفعل والهيولى بالقوة والصورة أحقَ باسم الجوهر من المركب لأنه من قبلها صار المركب

بالفعل وما تعدَّ سبب الشي هو أحقَ بذلاك المعنى

In Phys. 192 b 33

Del comentario (mayor): «Lo que aquí se manifiesta es que la materia solamente es sustancia en potencia, y que la forma es aquello gracias a los que el ente se hace sustancia en acto, de modo que el compuesto merece más el nombre de sustancia que la materia prima porque está en acto, y la materia prima está en potencia, y de modo que la forma merece más el nombre de sustancia que el compuesto, porque gracias a ella el compuesto existe en acto, y lo que se considera la causa de algo merece más este significado».

F. $49 \mathrm{M}-50$ A, Lib. II (t.c. 4): et apparet illic quod materia est substantia in potentia, et quod forma est illa, propter/quam ens est substantia in actu. Compositum igitur est dignius habere hoc nomen substantia quam materia, quia est in actu, et materia est in potentia: et forma est dignior habere hoc nomen substantia quam compositum, quoniam per illam est compositum in actu: et causa rei est dignior causato. 
(يقول القاضي في الشرح) و الطبيعة وما له طبيعة أي الهيولى والصورة كلاهما جوهر

وذلك أن الطبيعة التي تقال على الهيولى هي جوهر من قبل أنها موضوعة والطبيعة التي هي

الصورة هي جوهر من قبل أنها >في موضوع> يتقوم بها الموضوع وهو الذي دل عليه بقوله

$$
\text { دانما, لا أنهاكّ في موضوع/ }
$$

تثقوم بالموضوع كالأعر اض فمن هذا تبين أن كلي الطبيعين جوهر، ولاكن [يظهر]]

أن يكون [هو] المعنى مما يجب [أن] يتسلمه صاحب هذا العلم [من صاحب ] الفلسفة الولي أعني

أن الطبيعة المقولة على الصورة جوهر [و أما] أن الشي الطبيعي جوهر [بما] أمر [ ... ما كان ]

$$
\text { النظر في الجو هر مما تخصن هذا العلم [فالجوهر و] العرض [من] }
$$

فصول الموجود بما هو موجود والذي يظهر هنالك أن المادة هي جوهر بالقوة وأن

الصورة هي التي من قبلها صار الموجود جوهرأ بالفعل فالمركب أحقّ باسم الجوهر من الهيولي

لأنه بالفعل و الهيولي بالقوة

In Phys. 192 b 33

Dice el juez en su comentario (mayor): «La naturaleza y lo que tiene naturaleza, es decir, la materia prima y la forma, las dos son sustancia porque la naturaleza que se predica de la materia prima es sustancia por cuanto es sujeto, y la naturaleza que es la forma, es sustancia por cuanto "está en un sujeto" el sujeto persiste gracias a ella y es a lo se refiere (Aristóteles) con su expresión "siempre" no que (la forma) esté en un sujeto, [de que] persista en el sujeto como los accidentes, y de esto se manifiesta que las dos naturalezas son sustancia.

Sin embargo, [parece] que este significado pertenece a lo que el estudioso de esta ciencia tiene que recibir del estudioso de la filosofía primera, es decir, que la naturaleza predicada de la forma es sustancia,

${ }^{5}$ نه está excepcionalmente vocalizado en el manuscrito.

Al-Qanțara (AQ) XXX 1, enero-junio 2009, pp. 69-81 ISSN 0211-3589 
y que la cosa natural es sustancia, y que la investigación acerca de la sustancia es propia de esta ciencia [pues la sustancia] y el accidente son/diferencias del ente en cuanto ente, y lo que aquí se pone de manifiesto que la materia es sustancia en potencia, y que gracias a la forma el ente se hace sustancia, de modo que el compuesto merece más que la materia prima el nombre de sustancia porque está en acto, y la materia prima está en potencia».

F. 49 LM, Lib. II (t.c. 4) idest natura et habens naturam, scilicet materia et forma, vtrunque est substantia. natura enim quae dicitur de materia, est substantia, quia est subjecta, natura autem, quae est forma, est substantia, quae ${ }^{6}$ est in subjecto, quod sustentantur per illam. et hoc intendebat cum dixit «semper». non quia est in subjecto, per quod/sustentatur, sicut accidentia. et ex hoc declarabitur quod vtraque natura est substantia.

Sed videtur quod hoc concedendum est a Naturali, et accipit a Philosopho, scilicet, quod natura, quae dicitur de forma est substantia, et universaliter consyderare de substantia non est proprium huic scientiae. substantia enim et accidens sunt differentiae/entis secundum quod est ens. et apparet illic quod materia est substantia in potentia, et quod forma est illa, propter [F 50] quam ens est substantia in actu. compositum igitur est dignius habere hoc nomen substantia quam materia, quia est in actu, et materia est in potentia.

6

$$
\begin{aligned}
& \text { المبادي ثلث الصورة و العدم والموضوع } \\
& \text { المادة والصورة بالذات و العدم بالعرض: من شرح الصماع له }
\end{aligned}
$$

In Phys. 190 b 17

Los principios son tres, forma, materia y sujeto,

In Phys. 190 b 30

la materia y la forma [lo son] por esencia, y la privación, por accidente. Del comentario (mayor) suyo al De physico auditu.

${ }^{6}$ Quae = quia en Worcester Chapt. Libr., F. 96 (AL 388).

7 Así, pero lo correcto es: السماع.

Al-Qantara (AQ) XXX 1, enero-junio 2009, pp. 69-81 ISSN 0211-3589 
Fol. 39 A Lib. I (t.c. 65) Cum declarauit, quod principia sunt tria, Forma, et Priuatio, et subiectum,

Fol. 40 A, Lib. I (t.c. 67) Cum declarauit, quod principia per se sunt duo, materia et forma, et quod, si priuatio dicatur principio, est per accidens.

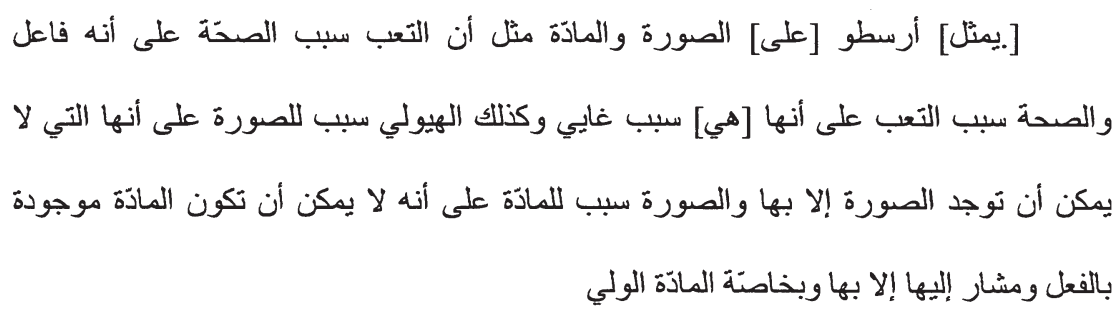

In Phys. 194 b 30

«Aristóteles pone el ejemplo de la materia y la forma de que el ejercicio físico es causa de la salud, en cuanto es agente, y la salud es causa del ejercicio en cuanto es causa final. Así la materia prima es causa de la forma en cuanto la forma no puede existir más que con ella, y la forma es causa de la materia en cuanto la materia no puede existir en acto y de manera concreta más que con ella, y sobre todo, la materia prima».

Fol. 60 I K, Lib. II (t.c. 30): verbi gratia, qum labor est causa sanitatis secundum agens, sanitas autem est causa laboris secundum finem. et similiter materia est causa formae, secundum quod forma non potest inueniri nisi per illam, forma autem est causa materiae, secundum quod materia non potest esse in actu et demonstrata nisi per illam, et precipue prima materia *. 
( قال في السماء والعالم) أن المتحرك دورا متحرّك بأجز ائه لا بكله وهنا فالجميع أجزائه

$$
\text { معا، يكمل دورته ، انظر هذا في الشي }
$$

In Phys. 212 b 14

Dijo en [el tratado] Acerca del cielo y el mundo: «El móvil circular se mueve con sus partes, no en su totalidad y aquí (pero) el todo son sus partes a la vez, completa su órbita» [Mira] esto en la cosa.

F. $141 \mathrm{H}$ Liber IV (t.c. 43) Et in hoc quod dixit Themistius, sunt questiones non modicae. qum quando dicit sphaera(m) moueri secundum omnes partes, et non mouetur secundum totum : et totum nihil aliud est quam partes.

In de Caelo, 217 a 22

Qvintum Volumen. Aristotelis de Coelo [...] cvm Averrois [...] commentariis, Venetiis, 1562.

Fol. 21 L, Liber I (t.c. 31): corpus rotundum... cum non moueatur in illis totaliter, sed partialiter.

Vemos que los fragmentos son de distinta extensión y calidad. En algunos, la cita es aproximada, como en el fragmento 3. En el fragmento 1 la traducción latina cubre solamente parte del árabe. En otros, la cita recoge dos frases distintas, como en el 6, y en el 8 no podemos saber si la cita imprecisa se refiere a Aristóteles o a Averroes, y si se se refiere realmente al De caelo o a la Física.

Quedan, ahora bien, los fragmentos 2, 4, 5 y 7, que son de gran exactitud; el 4 está incluido en el 5 . Todos proceden del comentario al Libro II de la Física, y el 4 y el 5 muestran un interés del lector anónimo por la relación de la sustancia con la forma, la materia prima y la naturaleza. Por desgracia, el fragmento 5 está en mal estado, y no he podido restablecer la lectura completa. A primera vista, el principal interés de los fragmentos está en sus diferencias con el texto latino.

Así observamos que en el texto latino, en todas sus variantes, dentro del fragmento 6, se lee et hoc intendebat cum dixit "semper». non quia est in subjecto, per quod / substentatur, sicut accidentia, y la cita 
de semper está más cerca de la primera versión de la traducción de Aristóteles, que repite el término semper est subjectum aliquod et in subiecto semper, como era de esperar, traducción de 192b 33-34 «Todas las cosas son sustancia, pues la naturaleza siempre es sujeto y está en un sujeto».

Como señalaba al principio, las variantes de las versiones latinas en el fragmento 5 son importantes. Agradezco al Dr. Schmieja que me las haya comunicado y reproduzco las de dos manuscritos:

\section{Manuscrito TOLEDO, BIBL. CAP. 97,1}

[...] a transmutatione. Deinde dixit: Et utrumque est substantia, natura enim quae dicitur de materia est substantia quae est subiecta. Natura autem quae est substantia forma est substantia quae est in subiecto quod sustentatur per illam et hoc intendebat cum dixit «semper», non quia est in subiecto per quod sustentatur sicut accidentia. Et ex hoc declarabitur quod utraque natura est subiecta/substantia.

Sed videtur quod hoc concedendum est a naturali et accipi a philosopho, scilicet quod natura / quae dicitur de forma est substantia, et universaliter considerare de substantia non est proprium huic scientiae. Substantia enim et accidens sunt differentiae entis secundum quod est ens. Et apparet illic quod materia est substantia in potentia, et quod forma est illa propter quam ens est substantia in actu. compositum igitur est dignius habere hoc nomen substantia quam materia quia est in actu et materia est in potentia.

\section{Manuscrito PARIS, BN, lat. 15453 (AL 654):}

[...] a transmutatione. Deinde dicit: Et utrumque est substantia, id est et natura et habens naturam scilicet materia et forma, utrumque est substantia. natura enim quae dicitur de materia, est substantia, quae est subiecta, natura autem, quae est forma, est substantia, quae est in subiecto, (i.m.: quod sustentatur per illam. et hoc intendebat cum dixit «semper». non quia est in subiecto) per quod/sustentatur, sicut accidentia. et ex hoc declarabitur quod utraque natura est substantia.

Sed videtur quod hoc concedendum est a naturali et accipi a philosopho, scilicet quod natura/quae dicitur de forma est substantia, et universaliter considerare de substantia non est proprium huic (exp.: substantiae) scientiae. Substantia enim et accidens sunt differentiae 
entis secundum quod est ens. Et apparet illic quod materia est substantia in potentia, et quod forma est illa propter quam ens est substantia in actu. (i.m.: compositum igitur est dignius habere hoc nomen substantia quam materia quia est in actu) et materia est in potentia et forma est dignior habere hoc nomen substantia quam compositum quoniam per illam est compositum in actu.

Puesto que el fragmento árabe 5 coincide con la impresión veneciana y con el manuscrito Worcester, Chapt. Libr., F. 96 (AL 388) podemos concluir, con toda cautela, que la tradición manuscrita común a la que pertenecen la versión latina de Venecia y Worcester deriva del manuscrito árabe cuyos fragmentos aquí publicamos.

Recibido: $17 / 01 / 2007$

Aceptado: 07/06/2007 